This is a peer-reviewed, accepted author manuscript of the following article: Biscay, J., Findlay, E., \& Dennany, L. (2020). Electrochemical monitoring of alcohol in sweat. Talanta, [121815].

\title{
Electrochemical Monitoring of Alcohol in Sweat
}

\author{
Julien Biscay ${ }^{1,2}$, Ewan Findlay, ${ }^{2}$ Lynn Dennany ${ }^{1 *}$ \\ WestChem \\ ${ }^{1}$ Department of Pure and Applied Chemistry \\ University of Strathclyde \\ Technology and Innovation Centre \\ 99 George Street \\ Glasgow, G1 1RD, UK \\ ${ }^{2}$ Buddi Ltd,
}

*corresponding author's email: lynn.dennany@strath.ac.uk 


\begin{abstract}
Rapid, periodic monitoring and detection of ethanol (EtOH) after consumption via a noninvasive measurement has been an area of increased research in recent years. Current point-ofcare or on-site detection strategies rely on single use sensors which are inadequate for monitoring during a longer period. A low cost, portable and novel approach is developed here for real-time monitoring over several days utilizing electrochemical techniques. The sensor shows oxidation of the ethanol in phosphate buffer and artificial sweat using the amperometric response from the application of $+0.9 \mathrm{~V}$ to the polyaniline modified screen printed electrode using $1 \mathrm{mM}$ ethanol as the averaged amount of ethanol eliminated in sweat after the consumption of one alcoholic beverage. Our enzyme based electrochemical sensor exhibits a qualitative assessment of the presence of ethanol in small volumes $(\leq 40 \mu \mathrm{L})$ of $0.1 \mathrm{M}$ sodium bicarbonate and subsequently artificial sweat, with 50 measurements taken daily over 11 days. While quantitative information is not obtained, the sensor system exhibits excellent stability after 3 months' dried storage in this complex biological matrix in an oxygen free cabinet. This addresses one of the key challenges for enzyme based electrochemical sensors, namely, the ability for real-time monitoring in complex biological matrices. The qualitative response illustrates the potential for this sensor to be exploited by non-experts which suggests the promise for their wider application in next-generation wearable electronics necessary for alcohol monitoring.
\end{abstract}

KEYWORDS: Electrochemical Sensing, Alcohol, Biological Matrices, Reusable device, Artificial Sweat 


\subsection{INTRODUCTION}

Alcohol is often considered as a "social lubricant"[1][2], or as a means of reducing inhibitions, reducing anxiety and improving well-being feeling or confidence. However, its heavy consumption can lead, in a short term, to an increase of criminality and physical aggressions[3], car accidents [4] or in a longer term to health problems affecting different organs (liver, pancreas etc.) [5].

The most common methods to detect alcohol are the ones based on body fluids[6] such as blood[7-9], urine[10][11], breath[12,13]. The major drawbacks of these samples are that an active participation of the person is required for collection and measurements. Moreover, in the case of the blood, the sensor can be quite invasive and relatively painful for some individuals.

Methods based on breath or blood analysis are useful for on field and "at the moment" measurement but show quickly their limitations if a periodic measurement is needed during a long period of time. Moreover, if analysis is needed on consecutive days, falsification of the samples can be done.

Thus the need of less invasive, wearable, robust sensors for the passive measurement of alcohol level (continuously over a long period of time) has grown during the last 10 years supported by parallel studies which show that it is possible to remotely monitor different parameters of interest (blood pressure, human localization)[14][15] in a non-invasive way.

Perspired sweat is a very attractive source of information due to ease of access, collection and analysis in comparison with the other biofluids previously mentioned. It can be sampled in a non-invasive way and does not require any action from the patient, which make it the ideal bio fluid for monitoring species of interest, especially in criminal justice system[16]. So research has focused on wearable alcohol sensors for continuous measurements [17-20] and a number studies have demonstrated that alcohol level in sweat can be correlated to the alcohol level in breath[21] and blood[7][22]. For the justice system, when a person is served with some form of control order, the sensor used should be able to detect when the offender ingests at least 1 alcoholised drink (0.65 - 1.50mM alcohol in sweat) [23]. However, challenges are associated with the limited amount of sweat which may be produced by the body under normal circumstances. To overcome this problem, induced sweat can be produced via pilocarpine electrophoresis[24,25]. This technique stresses the body to force it to produce sweat, offering 
then more sample to analyse to the sensor but unfortunately during a short period of time (30 $120 \mathrm{~min})[7][26]$.

The acidity of the sweat may cause the inactivation of the enzyme in the case of enzymatic sensors. The optimum working $\mathrm{pH}$ for the alcohol oxidase (AOX) from Pichia pastoris is 7.5 and issues surrounding activity when placed on an electrode surface have been suggested. Another important parameter to consider when developing a multi-use sensor, is the potential leakage of the enzyme from the sensing area of the device. Several immobilisation methods can be found in the literature from adsorption[27,28] to chemistry binding[29,30]. The adsorption method is the best to keep the activity of the enzyme intact, but this may result in leakage of the enzyme from the surface due to the weak attachment. Conversely, a strong attachment can result in the deactivation of the enzyme or reduction in the accessibility of the active sites of the enzyme[31].

At present, some wearable alcohol sensors are commercially available[32] or at a prototype stage [19]. Because these sensors can measure multiple time during several days, the data they generate can provide information's about days of abstinence, and even distinguish between heavy or sporadic alcohol ingestions.

One of the critical steps in the development of an electrochemical sensor is ensuring the transfer of the electrons involved in the reaction, from the sample to a sensor in a highly sensitive, accurate and repeatable manner. To this end, conducting polymer have been widely studied during the last decade along with making them suitable for biosensor applications[33] coupling it to enzymes[34-36], antibodies[37-39].

Moreover, the relative low cost of synthesis and monomer precursors, high biocompatibility and stability make the conducting polymers (CP) very attractive for sensor manufacture. This is especially true of polyaniline (PANI) and polypyrrole (Ppy)[40,41]. Focusing on the PANI[42-46], it can be obtained in 3 different oxidation states, with the only conductive one being emeraldine in it protonated form (emeraldine salt - ES(Figure 1A)). The PANI as other $\mathrm{CP}$ is reversibly oxidized from its leucoemeraldine form to emeraldine involving 2 electrons in the process. Because of the advantage of the inherent proprieties cited above, PANI has been used in biosensors as well as a mediator[47-54] or as an immobilization matrix [55] for the detection of a wide range of analytes such as ammonia [56,57], glucose [58,59], cholesterol[60-62]. 
Commercial screen-printed carbon electrodes modified with polyaniline are utilised within this contribution. These devices are ideal for the fabrication of biosensors with high sensitivity, selectivity and efficiency as the technique of screen-printing used in their manufacture is well controlled and developed to such a degree that it is relatively easy to reliably produce them at low cost in volume, yielding sensors with a high degree of reproducibility [63]. Moreover, there exist miniaturized variants of screen-printed electrodes making it possible to work with reduced sample volumes (few $\mu \mathrm{L}$ ). Finally, these devices have been used in a big range of applications[64-66] due to their easy modification with enzymes, antibodies, DNA, to name a few. This contribution describes a qualitative alcohol approach for the monitoring of alcohol in sweat.

\section{MATERIAL AND METHODS}

\subsection{Materials \& Reagents}

Alcohol oxidase (AOX) from Pichia Pastoris(10-40 units/mg protein, Figure1B), glutaraldehyde (Grade II, 25\% in $\left.\mathrm{H}_{2} \mathrm{O}\right), 117 \mathrm{Nafion}^{\circledR}(\sim 5 \%$ mixture of lower aliphatic alcohols and water), sodium bicarbonate ( $\geq 99.7 \%$, use as support electrolyte and control), potassium phosphate monobasic ( $\geq 98 \%$ ) and potassium phosphate dibasic $(\geq 98 \%)$ were purchased from Sigma-Aldrich. Urea, acetic acid (99.8 \%), lactic acid ( $\geq 85 \%$ ), ammonium chloride (99.5\%), sodium chloride ( $\geq 99.5 \%$ ), sodium hydroxide ( $\geq 98 \%$ ), were used to prepare artificial sweat following the ISO 3160-2 and were also supplied by Sigma-Aldrich. All chemicals were used as received. All solutions were prepared in Milli-Q water (18 M $2 . \mathrm{cm})$. Absolute ethanol (EtOH-99.8 \%) was supplied by VWR. $1 \mathrm{mM} \mathrm{EtOH}$ in $0.1 \mathrm{M}$ sodium bicarbonate or synthetic sweat were prepared daily for analysis. $\mathrm{AOX}(0.075 \mathrm{U} / \mu \mathrm{L})$ was prepared daily in $0.1 \mathrm{M}$ potassium phosphate buffer ( $\mathrm{pH} 7.5)$ as recommended by the supplier.

\subsection{Instrumentation}

Metrohm carbon screen printed electrodes (SPE) with a $4 \mathrm{~mm}$ carbon working electrode modified with PANI (reference:110PANI), with carbon counter electrode and Ag reference electrode was used throughout with a maximum of $40 \mu \mathrm{L}$ sample volume. To simulate a constant amount of sweat, a flow injection analysis (FIA) system (Metrohm) was used with the flow rate set at $0.1 \mathrm{~mL} / \mathrm{min}$. This delivered $\sim 1 \mathrm{~L}$ of buffer over the course of 7 days to the specifically designed flow cell containing the PANI SPEs. 


\subsection{Fabrication of AOX modified Electrode}

$5 \mu \mathrm{L}$ of $2.5 \% 117 \mathrm{Nafion}^{\circledR}$ was drop cast on to the working electrode and left to dry at room temperature. Afterwards, $40 \mu \mathrm{L}$ of $0.1 \%$ glutaraldehyde was deposited on the device and left to dry at room temperature during $5 \mathrm{~h}$. Finally, a washing step with Milli- $Q \mathrm{H}_{2} \mathrm{O}$ is performed before $40 \mu \mathrm{L}$ of $0.075 \mathrm{U} / \mu \mathrm{L}$ AOX is dropped on the electrode surface and left to dry at room temperature overnight (Figure 1C).

A

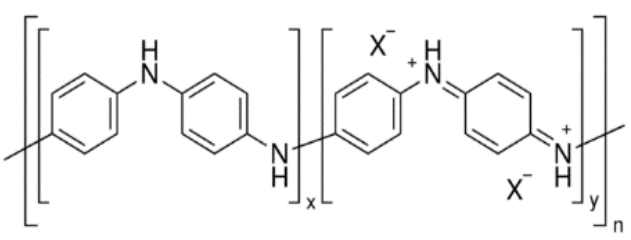

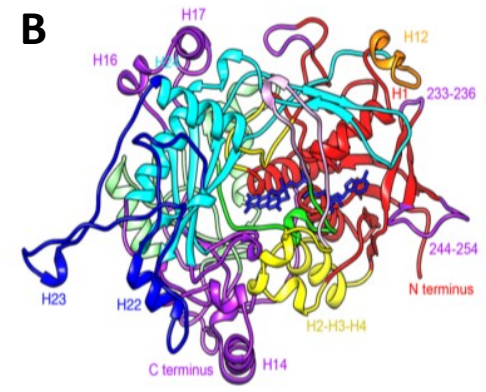

C

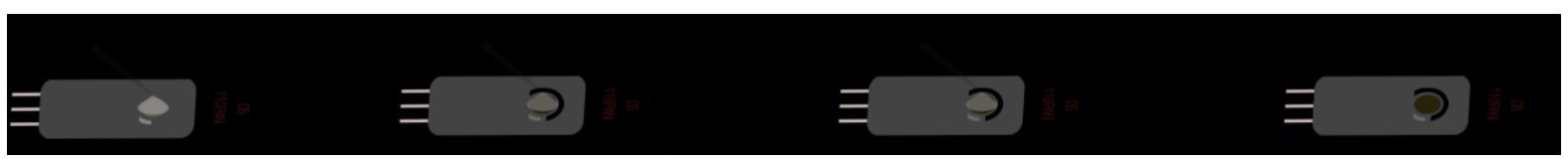

Figure 1. Structure of the Polyaniline(A), Structural domain[67] of the AOX monomer from Pichia Pastoris(B) and fabrication process of the sensor(C).

\section{RESULTS AND DISCUSSION}

\subsection{Electrochemical Detection of Alcohol}

In an enzymatic sensor, a critical component of the design is the immobilization of the protein on the surface of the device. This step becomes even more vital for a sensor that must perform several times over multiple days. To address this requirement, the incorporation of conducting polymers was evaluated. One of the main advantages of conducting polymers is their biocompatibility with enzymes. Therefore, electrodes modified with PANI were investigated. Figure 2A illustrates the typical electrochemical response observed for a PANI film, showing the oxidation the emeraldine to leucoemeraldine and the associated reduction. When the enzyme is deposited on the electrode surface, the redox process is still observed but with a lower intensity due to the layer of the loaded enzyme. This decrease after immobilization of enzyme has previously been observed for films after enzymes were deposited [61,68] and suggests that electron transfer is hindered or slowed during the electrochemical reaction following deposition. There are a range of strategies for the immobilization of proteins ranging from the simplest such as adsorption [69] to more elaborated ones based on covalent 
bonds[52,70-72] between species or cross linking[73], each of them with their own advantages and disadvantages. The main purpose of this work is to develop a sensor for the continuous monitoring of alcohol in sweat. Given the weakness of the bonds between AOX and PANI, the adsorption method would not be feasible. Therefore, a two-step approach using glutaraldehyde as a crosslinking agent between the enzyme and the polymer has been evaluated. A design of experiments has been done of 2 factors (concentration of AOX and percentage of glutaraldehyde) with 3 different levels for each of them. The results are provided in the supplementary information (Figure S1). It has been selected for further experiment, using 0.1 $\%$ glutaraldehyde and $0.075 \mathrm{U} / \mu \mathrm{L}$, as a compromised between an acceptable current and economically viable reagent.
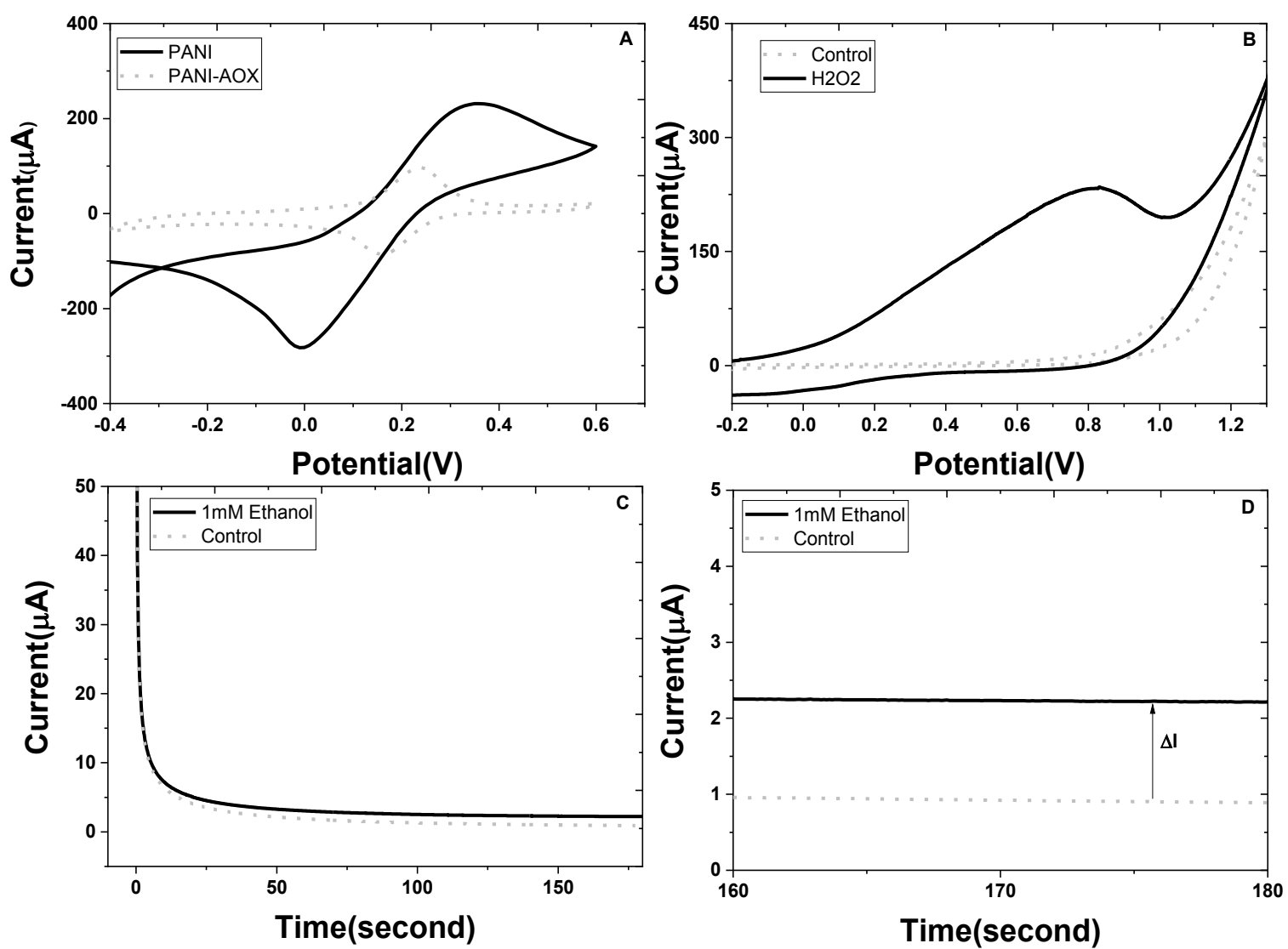

Figure 2. Cyclic voltammetry of PANI modified electrode (black solid line line(A)), PANI modified electrode after immobilisation of $A O X$ (grey short dash line $(A)$ ), $1 \mathrm{mM} \mathrm{H}_{2} \mathrm{O}_{2}$ (solid line $(B)$ ) and $0.1 \mathrm{M}$ $\mathrm{NaHCO}_{3}$ (short dash line(B)) on PANI modified electrode, recorded in $0.1 \mathrm{M} \mathrm{NaHCO}$ as supporting electrolyte at a scan rate of $50 \mathrm{mVs}^{-1}$ and Amperometric measurement ( $E_{\text {applied: }}+0.9 \mathrm{~V}$; time:180sec) of $1 \mathrm{mM} \mathrm{EtOH}$ (black solid line $(C$ and $D)$ and control (grey short dash line $(C$ and $D)$ ) prepared in $0.1 \mathrm{M}$ $\mathrm{NaHCO}_{3}$.

The mechanism of the enzymatic reaction is showed in Equation 1. The AOX will catalyse the reaction between the oxygen and the alcohol present in the sample to produce acetaldehyde 
and $\mathrm{H}_{2} \mathrm{O}_{2}$. Afterwards, the $\mathrm{H}_{2} \mathrm{O}_{2}$ enzymatically produced will be electrochemically oxidised applying a constant potential. This oxidation will be seen through an increase in the intensity of the current recorded (Figure S2). The current would be proportional to the amount of $\mathrm{H}_{2} \mathrm{O}_{2}$ generated and therefore provide an indirect measurement of the quantity of ethanol present in the sample.

$$
\begin{aligned}
& \text { Ethanol }+\mathrm{O}_{2} \stackrel{\mathrm{AOX}}{\longrightarrow} \text { Acetaldehyde }+\mathrm{H}_{2} \mathrm{O}_{2} \\
& \text { Equation 1. Enzymatic reaction on the sensing area. }
\end{aligned}
$$

The oxidation of the $\mathrm{H}_{2} \mathrm{O}_{2}$ on PANI modified electrodes has been reported to take place around $+0.6 \mathrm{~V}[74,75]$. On the Figure 2BError! Reference source not found., it can be observed how the oxidation of the hydrogen peroxide clearly appears at $+0.82 \mathrm{~V}$. This potential is higher than previously published by other groups detecting $\mathrm{H}_{2} \mathrm{O}_{2}$ on PANI modified electrodes, although for mixed PANI/carbon electrodes these higher potentials have been observed[76,77]. One of the explanations could be that the amount of polymer in the ratio carbon/PANI is unknown and could be different than the one published by other groups. Another reason for this shift to higher potential would be the method used by the supplier to prepare the electrode and the polymer (doping process, electrochemical method) as this can impact on the electrochemical properties of the conducting polymer[78,79] as has been shown previously.

Therefore, EtOH will be detected through the oxidation of the $\mathrm{H}_{2} \mathrm{O}_{2}$ present in the sample following reaction with AOX and monitored using amperometry. This is achieved by applying a constant potential during a period of time long enough to reach a plateau (Figure 2C). The shape of the amperogramm is characteristic of static system when the samples are not under any stirring action and are simply drop casted on the device[80-82]. The current which is recorded at this plateau is proportional to the concentration of $\mathrm{H}_{2} \mathrm{O}_{2}$ present in the sample and consequently to the amount of EtOH. The difference in intensity $(\Delta \mathrm{I})$ between the control and the sample is utilised to qualitatively determine if $\mathrm{EtOH}$ is present in an unknown sample, if the sensor was monitoring the sample continuously (Figure 2D). It is essential to apply the adequate potential obtaining the highest analytical response and the highest specificity. In cases where a nonspecific potential is applied, the resulting current may be contributed by several electroactive species[83]. The lowest effective potential was chosen to avoid potential oxidation of other electroactive species in complex biological samples at high oxidative potentials. To achieve this, different potentials, from $+0.2 \mathrm{~V}$ to $+0.9 \mathrm{~V}$ were applied for $180 \mathrm{~s}$ and the resultant currents are shown in the supplementary file (Figure S3). It can be observed that the intensity of the current increases with more positive potentials. We therefore utilised 
an applied voltage of $+0.9 \mathrm{~V}$ throughout this study. Those results are as expected viewing the shape of the cyclic voltammetry of Figure 2, where the maximum of the oxidation peak of the $\mathrm{H}_{2} \mathrm{O}_{2}$ was recorded around $+0.82 \mathrm{~V}$. It is not surprising to obtain the highest analytical response at $+0.9 \mathrm{~V}$. While the difference in response at 0.7 and $0.9 \mathrm{~V}$ on the $\mathrm{CV}$ is minimal, by holding the potential for $180 \mathrm{~s}$ results in a higher proportion of $\mathrm{H}_{2} \mathrm{O}_{2}$ undergoing oxidation following the interaction of EtOH with AOX, a more significant different in observed currents is observed in the chronoamperometry responses as seen in Figure S3. Note, higher potential have not been tested to limit as much as possible the interference's effect (dopamine $(+1.0 \mathrm{~V})$, paracetamol $(+1.1 \mathrm{~V}),[84,85]$ for instance or potential illicit substances[86]) at such positive potential, and for that reason, $+0.9 \mathrm{~V}$ was utilised for subsequent analysis. This potential is the lowest effective potential avoiding potential oxidation of interfering electroactive species in sweat.
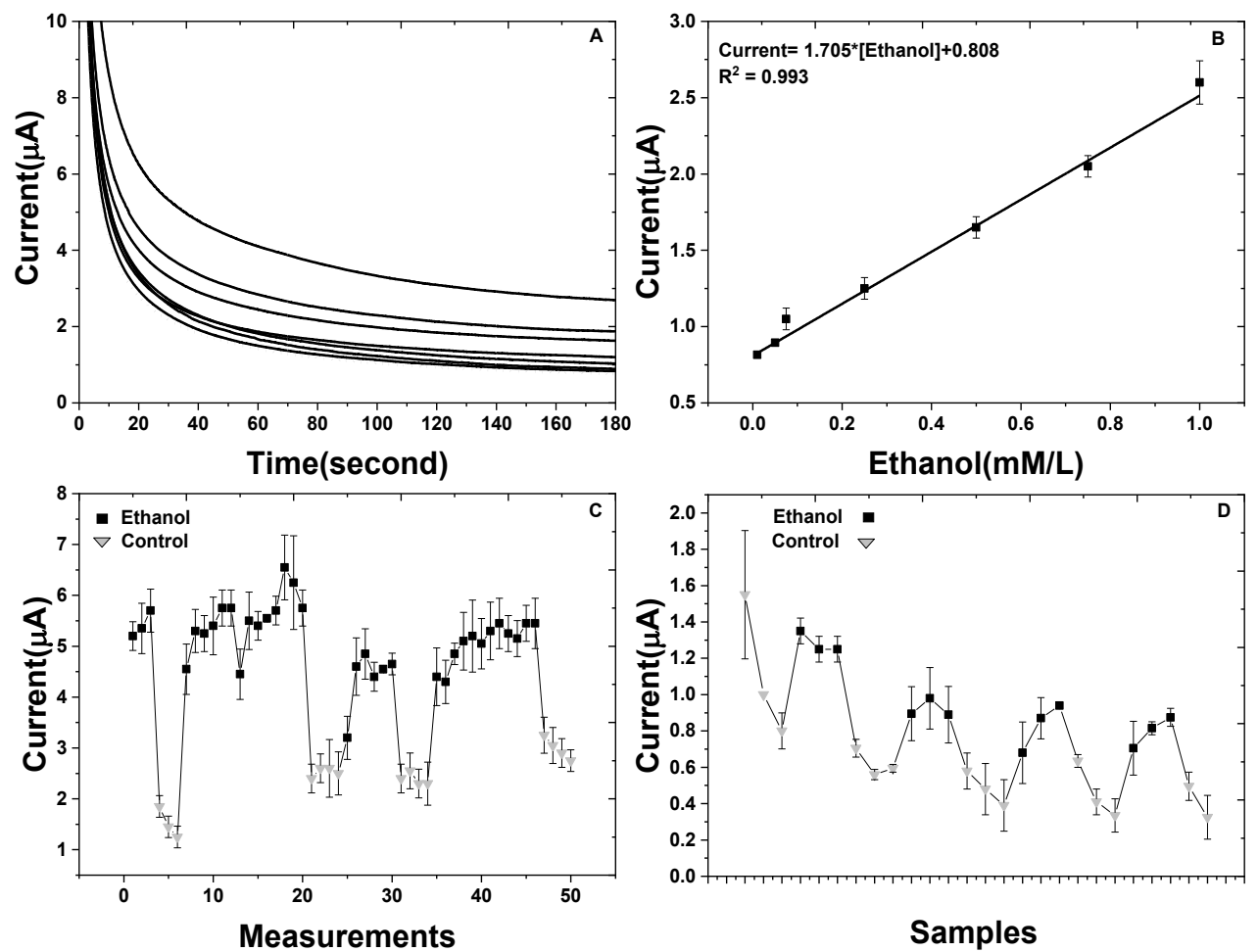

Figure 3. Amperometric detection(A) ( $E_{\text {applied: }}+0.9 \mathrm{~V}$; time:180s) of ethanol (black solid line) and control (grey short dash line). Corresponding calibration curves (inset), Consecutive measurements(B) of $1 \mathrm{mM} E t \mathrm{OH}$ (black squares) and control (grey triangles). Test of the sensor with $1 \mathrm{mM}$ EtOH (black squares) and control (grey triangles) after 3-month storage $(C)$. 


\subsection{Analytical performance}

The analytical performance of this approach was also examined. The influence of EtOH concentration on the current response was investigated over a concentration range of 0.01 to $1.00 \mathrm{mM}$ (Figure 3A). This range has been selected based on the work published by A. Bhide et al.[23] where they managed to detect alcohol in sweat after ingestion of 1-3 drinks (0.65-27 $\mathrm{mM}$ ) of alcoholic beverages. For each concentration of the calibration study, 3 different sensors have been prepared and the average of the 3 obtained currents is plotted. As illustrated in Figure 3AError! Reference source not found. and B, the current response increased linearly $(\mathrm{R} 2=$ 0.993) over this concentration range making the presented methodology suitable for the detection of small ingestions of alcohol. The detection limit (LOD) was calculated according to the $3 \mathrm{sb} / \mathrm{m}$ criteria, where $\mathrm{m}$ is the slope of the linear range of the corresponding calibration plot, and sb was estimated as the standard deviation of the intercept. The LOD value thus obtained was $0.045 \mathrm{mM} / \mathrm{L}$ which is 10 times lower than the amount of alcohol after the ingestion of 1 drink.

\subsection{Periodic detection of alcohol}

This work highlights the effectiveness of this approach for continuous monitoring of the presence of EtOH. Figure 3B illustrates the results obtained for an AOX-PANI modified electrode over 50 continuous scans over a 24-hour period, after a drop of $1 \mathrm{mM} \mathrm{EtOH} \mathrm{(black}$ squares) or control (triangles). The same electrodes were used throughout the 24-hour period (at least 50 times in one day). After 3 measurements of $1 \mathrm{mM} \mathrm{EtOH}$, a drop in the current is observed as expected when buffer has been placed on the device. The current increases again when $1 \mathrm{mM} \mathrm{EtOH}$ is dropped on the sensor. These increases and decreases in the current dependent on whether EtOH or control is sampled, which demonstrates the potential of this approach for a continuous monitoring of alcohol. The tendency in the general increase in the current recorded during each buffer analyses can be explained by the drying process. Alcohol traces may stay on the electrode surface and thus when the control buffer is tested the given response is due to the presence of alcohol in the previous tested sample. However, in every case the response increase if EtOH is added or decreases if a blank buffer solution is analysed highlighting that the approach can qualitatively determine if EtOH is present in the sample (Figure S4). This approach illustrates that the robustness of the sensor where it might be used over the course of 24-hours with over 50 measurements being taken while still being capable of providing qualitative information about the ingestion or not of small amount of EtOH (1 $\mathrm{mM}$ being the equivalent of approximately 1 drink[23]). To simulate more accurately, its use 
for monitoring the presence of EtOH in sweat, it was tested within a specifically designed flow cell with a continuous flow rate of $0.1 \mathrm{~mL} / \mathrm{min}$. This ensured that the sensor did not dry out over the course of a 24-hour period. At defined intervals, $20 \mu \mathrm{L}$ of buffer or $1 \mathrm{mM}$ EtOH were injected into the flow system, to simulate if $\mathrm{EtOH}$ had been consumed or not. As previously described, a voltage of $+0.9 \mathrm{~V}$ was applied to the electrode after injections for $30 \mathrm{~s}$ and the resultant current monitored. This was done in triplicate, over the course of 11 days (Figure S5), this approach is still able to qualitatively determine if EtOH is present or not. The 12 th day, no difference was observed between buffer and $1 \mathrm{mM} \mathrm{EtOH}$, showing a similar trend to previously published work [87]. The proposed methodology is quite promising especially given the harsher mechanical forces present when using a simulated FIA system. If attached to the surface of an individuals' skin, there is unlikely to be a high "flow" rate but more likely, the sample will evaporate with time and the volume of liquid on the sensor will be significantly lower. The goal of the FIA here is to maintain the electrode moisture content constantly. However, the flow rate generated by the pump may wash the electrode resulting in some enzyme leaking over the time, explaining the decrease in the current observed day to day. This washing effect would be considerably reduced on the skin of an individual. For these reasons the lifetime of the sensor is expected to increase when utilised on the surface of an individual.

\subsection{Long term stability}

Long term stability is another important parameter to take in account for potential future applications. Sensors have been prepared and after one hour drying at room temperature, the sensors are stored in a $\mathrm{O}_{2}$ free atmosphere for 90 days. After 3 months of storage, $40 \mu \mathrm{L}$ of 1 $\mathrm{mM} \mathrm{EtOH}$ or buffer is dropped successively on the different electrodes and amperometric measurements are performed by applying $+0.9 \mathrm{~V}$ as previously described, with typical results shown in Figure 3C. As it can be observed in Figure 3C, after 3 control measurements the sensor is showing an expected behaviour. The shape of the plotted result is the same as observed in the section 3.3. A response is still obtained after 3 months when the sensor is stored in an oxygen free atmosphere at room temperature, and a clear difference can be observed in the intensity of the current at the end of the amperometric measurements (Figure S6)). This long storage stability is longer than other enzymatic sensors based on screen printed electrodes for the detection of alcohol[88][89]which obtained a 6 weeks and 8 weeks storage stability respectively. Moreover, the intensity of the current increases when $1 \mathrm{mM} \mathrm{EtOH}$ is analysed after the control measurements and decreases when a control sample is measured after running the samples containing ethanol. This highlights the potential for future real-world applications. 


\subsection{Detection of alcohol in synthetic sweat}

In order to test the sensor in synthetic sweat, using the International Standardization Organization (ISO 105-E01:2013 Textiles and ISO 3160-2) recipe [90] the response of the system to $40 \mu \mathrm{L}$ of synthetic sweat (control) or $1 \mathrm{mM} \mathrm{EtOH}$ (prepared in synthetic sweat) was examined. As can been seen on the Figure S7 the sensor can distinguish between a sample containing alcohol and the control even in a complex matrix such as sweat. The reduced response was expected given the variety of components within sweat (salts, acids) which can interfere in the response or reducing the enzyme activity[91-93]. This highlights the potential of such as system to be applied to long-term continuous monitoring within a biological matrix. Further work examining a larger range of possible chemical interferences and utilising a model system closer resembling human skin is needed to showcase the potential translation of this approach, nonetheless this work illustrates a proof-of-concept for electrochemical sensors within the field of continuous monitoring.

\section{CONCLUSION}

This contribution illustrated the proof-of-concept for an electrochemical sensor within a continuous monitoring application. Utilising disposable screen-printed electrodes modified with a PANI containing AOX film, a low-cost alternative to the complex instrumentation currently utilised for analysis of such samples is offered. Here we propose a timely qualitative sensor for screening of the consumption of alcohol, on a periodic basis. The ability of this approach to determine the presence of EtOH was demonstrated over 11 days and to function after 3 months storage. Finally, the sensor successfully manages to distinguish between control and EtOH samples within artificial sweat and with the capacity to operate with extreme low volume of samples. Within many health and law enforcement environments an easily obtained and rapid "yes or no" answer to the consumption of EtOH is often required, a criterion met by our proposed methodology. Despite the complex nature of matrices such as sweat, we did not observe any significant interference effects which negatively impacted upon our qualitative analysis at relevant concentrations.

The proof-of-concept demonstrated within this contribution is strong, however further testing of the sensor is warranted. Current analysis has been performed on simulated scenarios utilising artificial sweat. In order to gain a greater understanding of the applicability of the current sensor it would be necessary to test the sensor upon other biological samples obtained following EtOH consumption. Further investigations into the impact of other commonly consumed substances 
such as medication, nicotine and / or illicit substances would also be of interest. Current investigations into the ability to negate the interference effect from naturally occurring species is on-going. Nevertheless, the current sensor design within the contribution demonstrates a promising avenue toward the expansion of electrochemical based sensors continuous individualised monitoring. 


\section{REFERENCES}

[1] G.F. Koob, M.A. Arends, M. Le Moal, Drug, Addiction and the Brain, in: Drug, Addict. Brain, 2014: pp. 173-219. https://doi.org/10.1016/B978-0-12-3869371.00006-4.

[2] J. Bell, Alcohol use disorders, Medicine (Baltimore). 44 (2016) 697-700. https://doi.org/10.1016/j.mpmed.2016.09.001.

[3] B. Hansen, G.R. Waddell, Legal access to alcohol and criminality, J. Health Econ. 57 (2018) 277-289. https://doi.org/10.1016/j.jhealeco.2017.08.001.

[4] J. Yao, R.B. Voas, J.H. Lacey, Drivers with alcohol use disorders and their risks of crash involvement, Drug Alcohol Depend. 183 (2018) 210-216. https://doi.org/10.1016/j.drugalcdep.2017.10.040.

[5] M.A. Schuckit, Alcohol-use disorders, Lancet. 373 (2009) 492-501. https://doi.org/10.1016/S0140-6736(09)60009-X.

[6] A. Dasgupta, Measurement of Alcohol Levels in Body Fluids and Transdermal Alcohol Sensors, Alcohol Its Biomarkers. (2015) 65-90. https://doi.org/10.1016/B9780-12-800339-8.00003-1.

[7] M. Gamella, S. Campuzano, J. Manso, G.G. de Rivera, F. López-Colino, A.J. Reviejo, J.M. Pingarrón, A novel non-invasive electrochemical biosensing device for in situ determination of the alcohol content in blood by monitoring ethanol in sweat, Anal. Chim. Acta. 806 (2014) 1-7. https://doi.org/10.1016/j.aca.2013.09.020.

[8] J. Aymerich, A. Márquez, L. Terés, X. Muñoz-Berbel, C. Jiménez, C. Domínguez, F. Serra-Graells, M. Dei, Cost-effective smartphone-based reconfigurable electrochemical instrument for alcohol determination in whole blood samples, Biosens. Bioelectron. 117 (2018) 736-742. https://doi.org/10.1016/j.bios.2018.06.044.

[9] A. Shenhav, Z. Brodie, Y. Beiderman, J. Garcia, V. Mico, Z. Zalevsky, Optical sensor for remote estimation of alcohol concentration in blood stream, Opt. Commun. 289 (2013) 149-157. https://doi.org/10.1016/j.optcom.2012.09.079.

[10] L. Correa, R.C. Ped, Headspace gas chromatography with capillary column for urine alcohol determination ristiana, J. Chromatogr. B. 704 (1997) 365-368. https://doi.org/10.1016/S0378-4347(97)00445-3.

[11] H. Lidén, A.R. Vijayakumar, L. Gorton, G. Marko-Varga, Rapid alcohol determination in plasma and urine by column liquid chromatography with biosensor detection, J. Pharm. Biomed. Anal. 17 (1998) 1111-1128. https://doi.org/10.1016/s07317085(98)00077-6.

[12] M.R. Rahman, J.T.S. Allan, M. Zamanzad Ghavidel, L.E. Prest, F.S. Saleh, E.B. Easton, The application of power-generating fuel cell electrode materials and monitoring methods to breath alcohol sensors, Sensors Actuators, B Chem. 228 (2016) 448-457. https://doi.org/10.1016/j.snb.2016.01.061.

[13] K.I. Ozoemena, S. Musa, R. Modise, A.K. Ipadeola, L. Gaolatlhe, S. Peteni, G. Kabongo, Fuel cell-based breath-alcohol sensors: Innovation-hungry old electrochemistry, Curr. Opin. Electrochem. 10 (2018) 82-87. https://doi.org/10.1016/j.coelec.2018.05.007.

[14] C.T. Recchiuto, A. Scalmato, A. Sgorbissa, A dataset for human localization and mapping with wearable sensors, Rob. Auton. Syst. 97 (2017) 136-143. https://doi.org/10.1016/j.robot.2017.08.004.

[15] Y. Athavale, S. Krishnan, Biosignal monitoring using wearables : Observations and opportunities, Biomed. Signal Process. Control. 38 (2017) 22-33. https://doi.org/10.1016/j.bspc.2017.03.011.

[16] A. Dasgupta, Methods of alcohol measurement, in: Alcohol, Drugs, Genes Clin. Lab., 
Elsevier Inc., 2017: pp. 155-166. https://doi.org/10.1016/B978-0-12-805455-0.000099.

[17] P.D. Thungon, A. Kakoti, L. Ngashangva, P. Goswami, Advances in developing rapid, reliable and portable detection systems for alcohol, Biosens. Bioelectron. 97 (2017) 83-99. https://doi.org/10.1016/j.bios.2017.05.041.

[18] A.S. Campbell, J. Kim, J. Wang, Wearable electrochemical alcohol biosensors, Curr. Opin. Electrochem. 10 (2018) 126-135. https://doi.org/10.1016/j.coelec.2018.05.014.

[19] Y. Wang, D.J. Fridberg, R.F. Leeman, R.L. Cook, E.C. Porges, Wrist-Worn Alcohol Biosensors: Strengths, Limitations, and Future Directions, Alcohol. (2018). https://doi.org/10.1016/J.ALCOHOL.2018.08.013.

[20] W. Roberts, S.A. Mckee, Mobile alcohol biosensors and pharmacotherapy development research, Alcohol. 81 (2019) 149-160. https://doi.org/10.1016/j.alcohol.2018.07.012.

[21] M. Sirlanci, I.G. Rosen, T.L. Wall, S.E. Luczak, Applying a Novel Population-Based Model Approach to Estimating Breath Alcohol Concentration (BrAC) from Transdermal Alcohol Concentration (TAC) Biosensor Data, Alcohol. (2018). https://doi.org/https://doi.org/10.1016/j.alcohol.2018.09.005.

[22] M. Gamella, S. Campuzano, J. Manso, G.G. de Rivera, F. López-Colino, A.J. Reviejo, J.M. Pingarrón, A novel non-invasive electrochemical biosensing device for in situ determination of the alcohol content in blood by monitoring ethanol in sweat, Anal. Chim. Acta. 806 (2014) 1-7. https://doi.org/10.1016/j.aca.2013.09.020.

[23] A. Bhide, S. Muthukumar, S. Prasad, CLASP (Continuous lifestyle awareness through sweat platform): A novel sensor for simultaneous detection of alcohol and glucose from passive perspired sweat, Biosens. Bioelectron. 117 (2018) 537-545. https://doi.org/10.1016/j.bios.2018.06.065.

[24] E. V. Karpova, E.E. Karyakina, A.A. Karyakin, Wearable non-invasive monitors of diabetes and hypoxia through continuous analysis of sweat, Talanta. 215 (2020) 120922. https://doi.org/10.1016/j.talanta.2020.120922.

[25] P. Simmers, S.K. Li, G. Kasting, J. Heikenfeld, Prolonged and localized sweat stimulation by iontophoretic delivery of the slowly-metabolized cholinergic agent carbachol, J. Dermatol. Sci. 89 (2018) 40-51.

https://doi.org/10.1016/j.jdermsci.2017.10.013.

[26] S. Emaminejad, W. Gao, E. Wu, Z.A. Davies, H.Y.Y. Nyein, S. Challa, S.P. Ryan, H.M. Fahad, K. Chen, Z. Shahpar, S. Talebi, C. Milla, A. Javey, R.W. Davis, Autonomous sweat extraction and analysis applied to cystic fibrosis and glucose monitoring using a fully integrated wearable platform, Proc. Natl. Acad. Sci. U. S. A. 114 (2017) 4625-4630. https://doi.org/10.1073/pnas.1701740114.

[27] R.E. Kim, S.G. Hong, S. Ha, J. Kim, Enzyme adsorption, precipitation and crosslinking of glucose oxidase and laccase on polyaniline nanofibers for highly stable enzymatic biofuel cells, Enzyme Microb. Technol. 66 (2014) 35-41.

https://doi.org/10.1016/j.enzmictec.2014.08.001.

[28] H. Zhang, Z. Fan, J. Li, L. Han, A comparative study on enzyme adsorption and hydrolytic performance of different scale corn stover by two-step kinetics, Bioresour. Technol. 282 (2019) 384-389. https://doi.org/10.1016/j.biortech.2019.03.005.

[29] J.H. Yang, H.R. Kim, J.H. Lee, J.H. Jin, H.U. Lee, S.W. Kim, Electrochemical properties of enzyme electrode covalently immobilized on a graphite oxide/cobalt hydroxide/chitosan composite mediator for biofuel cells, Int. J. Hydrogen Energy. (2020). https://doi.org/10.1016/j.ijhydene.2020.03.084.

[30] F. Peng, X.Y. Ou, Z.W. Guo, Y.J. Zeng, M.H. Zong, W.Y. Lou, Co-immobilization of multiple enzymes by self-assembly and chemical crosslinking for cofactor 
regeneration and robust biocatalysis, Int. J. Biol. Macromol. 162 (2020) 445-453. https://doi.org/10.1016/j.ijbiomac.2020.06.141.

[31] D.M. Liu, J. Chen, Y.P. Shi, Advances on methods and easy separated support materials for enzymes immobilization, TrAC - Trends Anal. Chem. 102 (2018) 332342. https://doi.org/10.1016/j.trac.2018.03.011.

[32] S.M. Alessi, N.P. Barnett, N.M. Petry, Experiences with SCRAMx alcohol monitoring technology in 100 alcohol treatment outpatients, Drug Alcohol Depend. 178 (2017) 417-424. https://doi.org/10.1016/j.drugalcdep.2017.05.031.

[33] A.J. Hackett, J. Malmström, J. Travas-Sejdic, Functionalization of conducting polymers for biointerface applications, Prog. Polym. Sci. 70 (2017) 18-33. https://doi.org/10.1016/j.progpolymsci.2017.03.004.

[34] S. Lata, B. Batra, N. Singala, C.S. Pundir, Chemical Construction of amperometric 1 amino acid biosensor based on 1 -amino acid oxidase immobilized onto ZnONPs / cMWCNT / PANI / AuE, Sensors Actuators B. Chem. 188 (2013) 1080-1088. https://doi.org/10.1016/j.snb.2013.08.025.

[35] B. Nohwal, R. Chaudhary, P. Kumar, C.S. Pundir, Fabrication and application of an amperometric lysine biosensor based on covalently immobilized lysine oxidase nanoparticles onto Au electrode, Int. J. Biol. Macromol. 146 (2020) 907-915. https://doi.org/10.1016/j.ijbiomac.2019.09.213.

[36] V.G. Pahurkar, Y.S. Tamgadge, A.B. Gambhire, G.G. Muley, Chemical Glucose oxidase immobilized PANI cladding modified fiber optic intrinsic biosensor for detection of glucose, Sensors Actuators B. Chem. 210 (2015) 362-368. https://doi.org/10.1016/j.snb.2014.12.125.

[37] A. Zhang, W. Guo, H. Ke, X. Zhang, H. Zhang, C. Huang, Sandwich-format ECL immunosensor based on Au star@BSA-Luminol nanocomposites for determination of human chorionic gonadotropin, Biosens. Bioelectron. 101 (2018) 219-226. https://doi.org/10.1016/j.bios.2017.10.040.

[38] J. Miao, X. Li, Y. Li, X. Dong, G. Zhao, J. Fang, Q. Wei, Dual-signal sandwich electrochemical immunosensor for amyloid $\mathrm{b}$-protein detection based on $\mathrm{Cu}$ e $\mathrm{Al} 2 \mathrm{O}$ 3 -g e C 3 N 4 e Pd and, Anal. Chim. Acta. 1089 (2019) 48-55. https://doi.org/10.1016/j.aca.2019.09.017.

[39] N. Ruecha, K. Shin, O. Chailapakul, N. Rodthongkum, Chemical Label-free paperbased electrochemical impedance immunosensor for human interferon gamma detection, Sensors Actuators B. Chem. 279 (2019) 298-304. https://doi.org/10.1016/j.snb.2018.10.024.

[40] S.K. Shukla, C.S. Kushwaha, N.B. Singh, Recent developments in conducting polymer based composites for sensing devices, Mater. Today Proc. 4 (2017) 5672-5681. https://doi.org/10.1016/j.matpr.2017.06.029.

[41] P. Humpolíček, V. Kašpárková, J. Pacherník, J. Stejskal, P. Bober, Z. Capáková, K.A. Radaszkiewicz, I. Junkar, M. Lehocký, The biocompatibility of polyaniline and polypyrrole: A comparative study of their cytotoxicity, embryotoxicity and impurity profile, Mater. Sci. Eng. C. 91 (2018) 303-310. https://doi.org/10.1016/j.msec.2018.05.037.

[42] N. Gull, S.M. Khan, A. Islam, M.T.Z. Butt, T. Jamil, Modification of Polyaniline, Elsevier, 2018. https://doi.org/10.1016/B978-0-12-809551-5.00003-5.

[43] M.Y. Hua, G.W. Hwang, Y.H. Chuang, S.A. Chen, R.Y. Tsai, Soluble n-doped polyaniline: Synthesis and characterization, Macromolecules. 33 (2000) 6235-6238. https://doi.org/10.1021/ma000376x.

[44] J. Scotto, M.I. Florit, D. Posadas, $\mathrm{pH}$ dependence of the voltammetric response of Polyaniline, J. Electroanal. Chem. 785 (2017) 14-19. 
https://doi.org/10.1016/j.jelechem.2016.11.066.

[45] H. Zhang, J. Wang, X. Gao, Z. Wang, S. Wang, The electrochemical activity of polyaniline: An important issue on its use in electrochemical energy storage devices, Synth. Met. 187 (2014) 46-51. https://doi.org/10.1016/j.synthmet.2013.10.022.

[46] G. Ciric-Marjanovic, Recent advances in polyaniline research: Polymerization mechanisms, structural aspects, properties and applications, Synth. Met. 177 (2013) 147. https://doi.org/10.1016/j.synthmet.2013.06.004.

[47] C. Dhand, G. Sumana, M. Datta, B.D. Malhotra, Electrophoretically deposited nanostructured polyaniline film for glucose sensing, Thin Solid Films. 519 (2010) 11451150. https://doi.org/10.1016/j.tsf.2010.08.059.

[48] H. Zhong, R. Yuan, Y. Chai, W. Li, X. Zhong, Y. Zhang, In situ chemo-synthesized multi-wall carbon nanotube-conductive polyaniline nanocomposites: Characterization and application for a glucose amperometric biosensor, Talanta. 85 (2011) 104-111. https://doi.org/10.1016/j.talanta.2011.03.040.

[49] K. Grennan, A.J. Killard, C.J. Hanson, A.A. Cafolla, M.R. Smyth, Optimisation and characterisation of biosensors based on polyaniline, Talanta. 68 (2006) 1591-1600. https://doi.org/10.1016/j.talanta.2005.08.036.

[50] L. Dennany, E.J. O’Reilly, P.C. Innis, G.G. Wallace, R.J. Forster, Solid state photochemistry of novel composites containing luminescent metal centers and poly(2methoxyaniline-5-sulfonic acid), J. Phys. Chem. B. 113 (2009) 7443-7448. https://doi.org/10.1021/jp901808d.

[51] A. Venkatanarayanan, A.M. Spehar-Délèze, L. Dennany, Y. Pellegrin, T.E. Keyes, R.J. Forster, Ruthenium aminophenanthroline metallopolymer films electropolymerized from an ionic liquid: Deposition and electrochemical and photonic properties, Langmuir. 24 (2008) 11233-11238. https://doi.org/10.1021/la8011316.

[52] L. Dennany, P.C. Innis, S.T. McGovern, G.G. Wallace, R.J. Forster, Electronic interactions within composites of polyanilines formed under acidic and alkaline conditions. Conductivity, ESR, Raman, UV-vis and fluorescence studies, Phys. Chem. Chem. Phys. 13 (2011) 3303-3310. https://doi.org/10.1039/c0cp00699h.

[53] L. Dennany, E.J. O’Reilly, P.C. Innis, G.G. Wallace, R.J. Forster, The influence of poly(2-methoxyaniline-5-sulfonic acid) on the electrochemical and photochemical properties of a highly luminescent ruthenium complex, Electrochim. Acta. 53 (2008) 4599-4605. https://doi.org/10.1016/j.electacta.2007.11.025.

[54] L. Dennany, P.C. Innis, G.G. Wallace, R.J. Forster, Reversible photoinduced electron transfer in a ruthenium poly(2-methoxyaniline-5-sulfonic acid) composite film, J. Phys. Chem. B. 112 (2008) 12907-12912. https://doi.org/10.1021/jp804213r.

[55] X. Feng, H. Cheng, Y. Pan, H. Zheng, Development of glucose biosensors based on nanostructured graphene-conducting polyaniline composite, Biosens. Bioelectron. 70 (2015) 411-417. https://doi.org/10.1016/j.bios.2015.03.046.

[56] N.R. Tanguy, M. Thompson, N. Yan, A review on advances in application of polyaniline for ammonia detection, Sensors Actuators, B Chem. 257 (2018) 10441064. https://doi.org/10.1016/j.snb.2017.11.008.

[57] Z. Guo, N. Liao, M. Zhang, W. Xue, Theoretical approach to evaluate graphene / PANI composite as highly selective ammonia sensor, Appl. Surf. Sci. 453 (2018) 336340. https://doi.org/10.1016/j.apsusc.2018.05.108.

[58] M. Xu, Y. Song, Y. Ye, C. Gong, Y. Shen, L. Wang, L. Wang, A novel flexible electrochemical glucose sensor based on gold nanoparticles/polyaniline arrays/carbon cloth electrode, Sensors Actuators, B Chem. 252 (2017) 1187-1193. https://doi.org/10.1016/j.snb.2017.07.147.

[59] S. Kailasa, B. Geeta, N. Jayarambabu, R.K. Kumar, S. Sharma, K.V. Rao, Conductive 
Polyaniline Nanosheets ( CPANINS ) for a non-enzymatic glucose sensor, Mater. Lett. 245 (2019) 118-121. https://doi.org/10.1016/j.matlet.2019.02.103.

[60] C. Dhand, S.K. Arya, M. Datta, B.D. Malhotra, Polyaniline - carbon nanotube composite film for cholesterol biosensor, Anal. Biochem. 383 (2008) 194-199. https://doi.org/10.1016/j.ab.2008.08.039.

[61] R. Khan, A. Kaushik, A.P. Mishra, Immobilization of cholesterol oxidase onto electrochemically polymerized film of biocompatible polyaniline-Triton X-100, Mater. Sci. Eng. C. 29 (2009) 1399-1403. https://doi.org/10.1016/j.msec.2008.11.001.

[62] R. Khan, P.R. Solanki, A. Kaushik, S.P. Singh, S. Ahmad, B.D. Malhotra, Cholesterol biosensor based on electrochemically prepared polyaniline conducting polymer film in presence of a nonionic surfactant, J. Polym. Res. 16 (2009) 363-373. https://doi.org/10.1007/s10965-008-9237-8.

[63] Z. Taleat, A. Khoshroo, Screen-printed electrodes for biosensing: a review (2008 2013), Microchim. Acta. 181 (2014) 865-891. https://doi.org/10.1007/s00604-0141181-1.

[64] M. Trojanowicz, Impact of nanotechnology on design of advanced screen-printed electrodes for different analytical applications, Trends Anal. Chem. 84 (2016) 22-47. https://doi.org/10.1016/j.trac.2016.03.027.

[65] R.A.S. Couto, J.L.F.C. Lima, M.B. Quinaz, Recent developments, characteristics and potential applications of screen-printed electrodes in pharmaceutical and biological analysis, Talanta. 146 (2016) 801-814. https://doi.org/10.1016/j.talanta.2015.06.011.

[66] H.M. Mohamed, Screen-printed disposable electrodes : Pharmaceutical applications and recent developments, Trends Anal. Chem. 82 (2016) 1-11. https://doi.org/10.1016/j.trac.2016.02.010.

[67] J. Vonck, D.N. Parcej, D.J. Mills, Structure of alcohol oxidase from pichia pastoris by cryo-electron microscopy, PLoS One. 11 (2016) 1-20. https://doi.org/10.1371/journal.pone.0159476.

[68] S. Singh, R. Singhal, B.D. Malhotra, Immobilization of cholesterol esterase and cholesterol oxidase onto sol-gel films for application to cholesterol biosensor, Anal. Chim. Acta. 582 (2007) 335-343. https://doi.org/10.1016/j.aca.2006.09.010.

[69] A.P.M. Tavares, C.G. Silva, G. Draz, J.L. Faria, Laccase immobilization over multiwalled carbon nanotubes : Kinetic , thermodynamic and stability studies ${ }^{\wedge}$ ic, J. Colloid Interface Sci. 454 (2015) 52-60. https://doi.org/10.1016/j.jcis.2015.04.054.

[70] D. Liu, J. Chen, Y. Shi, Tyrosinase immobilization on aminated magnetic nanoparticles by physical adsorption combined with covalent crosslinking with improved catalytic activity, reusability and storage stability, Anal. Chim. Acta. 1006 (2018) 90-98. https://doi.org/10.1016/j.aca.2017.12.022.

[71] L. Dennany, P.C. Innis, F. Masdarolomoor, G.G. Wallace, ESR, Raman, and conductivity studies on fractionated poly(2-methoxyaniline- 5-sulfonic acid), J. Phys. Chem. B. 114 (2010) 2327-2341. https://doi.org/10.1021/jp908005m.

[72] R.D. Henderson, M.C. Breadmore, L. Dennany, R.M. Guijt, P.R. Haddad, E.F. Hilder, P.C. Innis, T.W. Lewis, G.G. Wallace, Photolithographic patterning of conducting polyaniline films via flash welding, Synth. Met. 160 (2010) 1405-1409. https://doi.org/10.1016/j.synthmet.2010.04.018.

[73] J. Gao, W. Kong, L. Zhou, Y. He, L. Ma, Y. Wang, L. Yin, Y. Jiang, Monodisperse core-shell magnetic organosilica nanoflowers with radial wrinkle for lipase immobilization, Chem. Eng. J. 309 (2017) 70-79. https://doi.org/10.1016/j.cej.2016.10.021.

[74] V. Gautam, K.P. Singh, V.L. Yadav, Polyaniline/multiwall carbon nanotubes/starch nanocomposite material and hemoglobin modified carbon paste electrode for hydrogen 
peroxide and glucose biosensing, Int. J. Biol. Macromol. 111 (2018) 1124-1132. https://doi.org/10.1016/j.ijbiomac.2018.01.094.

[75] Y. Yang, S. Mu, Determination of hydrogen peroxide using amperometric sensor of polyaniline doped with ferrocenesulfonic acid, Biosens. Bioelectron. 21 (2005) 74-78. https://doi.org/10.1016/j.bios.2004.08.049.

[76] P. Santhosh, K.M. Manesh, A. Gopalan, K.P. Lee, Fabrication of a new polyaniline grafted multi-wall carbon nanotube modified electrode and its application for electrochemical detection of hydrogen peroxide, Anal. Chim. Acta. 575 (2006) 32-38. https://doi.org/10.1016/j.aca.2006.05.075.

[77] E. Kazimierska, M. Muchindu, A. Morrin, E. Iwuoha, M.R. Smyth, A.J. Killard, The fabrication of structurally multiordered polyaniline films and their application in electrochemical sensing and biosensing, Electroanalysis. 21 (2009) 595-603. https://doi.org/10.1002/elan.200804455.

[78] S. Bilal, A. Akbar, A.U.H.A. Shah, Highly selective and reproducible electrochemical sensing of ascorbic acid through a conductive polymer coated electrode, Polymers (Basel). 11 (2019). https://doi.org/10.3390/polym11081346.

[79] R. Prakash, Electrochemistry of polyaniline: Study of the $\mathrm{pH}$ effect and electrochromism, J. Appl. Polym. Sci. 83 (2002) 378-385. https://doi.org/10.1002/app.10025.

[80] E.A. Khudaish, A.A. Al Farsi, Electrochemical oxidation of dopamine and ascorbic acid at a palladium electrode modified with in situ fabricated iodine-adlayer in alkaline solution, Talanta. 80 (2010) 1919-1925. https://doi.org/10.1016/j.talanta.2009.10.044.

[81] D. Maity, C.R. Minitha, R.K.R. T, Materials Science \& Engineering C Glucose oxidase immobilized amine terminated multiwall carbon nanotubes / reduced graphene oxide / polyaniline / gold nanoparticles modi fi ed screen-printed carbon electrode for highly sensitive amperometric glucose dete, Mater. Sci. Eng. C. 105 (2019) 110075. https://doi.org/10.1016/j.msec.2019.110075.

[82] P.T. Garcia, L.N. Guimarães, A.A. Dias, C.J. Ulhoa, W.K.T. Coltro, Sensors and Actuators B : Chemical Amperometric detection of salivary alpha-amylase on screenprinted carbon electrodes as a simple and inexpensive alternative for point-of-care testing, Sensors Actuators B. Chem. 258 (2018) 342-348. https://doi.org/10.1016/j.snb.2017.11.068.

[83] S. Adeloju, Amperometry, in: 2005: p. 70.

[84] A. Stewart, J. Hendry, L. Dennany, Whole Blood Electrochemiluminescent Detection of Dopamine, Anal. Chem. 87 (2015) 11847-11853.

[85] A. Stewart, K. Brown, L. Dennany, Cathodic Quantum Dot Facilitated Electrochemiluminescent Detection in Blood, Anal. Chem. 90 (2018) 12944-12950.

[86] J. McGeehan, Dennan, Electrochemiluminescent detection of methamphetamine and amphetamine, Forensic Sci. Int. 264 (2016) 1-6.

[87] J. Razumiene, V. Gureviciene, V. Laurinavicius, J.V. Grazulevicius, Amperometric detection of glucose and ethanol in beverages using flow cell and immobilised on screen-printed carbon electrode PQQ-dependent glucose or alcohol dehydrogenases, Sensors Actuators A. Phys. 78 (2001) 243-248.

[88] M. Bilgi, E. Ayranci, Biosensor application of screen-printed carbon electrodes modified with nanomaterials and a conducting polymer : Ethanol biosensors based on alcohol dehydrogenase, Sensors Actuators B. Chem. 237 (2016) 849-855. https://doi.org/10.1016/j.snb.2016.06.164.

[89] E. Costa Rama, J. Biscay, M.B. González García, a. J. Reviejo, J.M. Pingarrón Carrazón, A. Costa García, Comparative study of different alcohol sensors based on Screen-Printed Carbon Electrodes, Anal. Chim. Acta. 728 (2012) 69-76. 
https://doi.org/10.1016/j.aca.2012.03.039.

[90] Bertrand R. Brunet, A.J. Barnes, P.M. Karl B. Scheidweiler, M.A. Huestis, Development and validation of a solid-phase extraction gas chromatography-mass spectrometry method for the simultaneous quantification of methadone, heroin, cocaine and metabolites in sweat., Anal. Bioanal. Chem. 392 (2008) 115-127.

[91] R. Bennett, D. Leech, Improved operational stability of mediated glucose enzyme electrodes for operation in human physiological solutions, Bioelectrochemistry. 133 (2020) 107460. https://doi.org/10.1016/j.bioelechem.2020.107460.

[92] J. Wang, Electrochemical glucose biosensors, Chem. Rev. 108 (2008) 814-825. https://doi.org/10.1021/cr068123a.

[93] G. Reach, S.W. George, Can Continuous Glucose Monitoring Be Used for the Treatment of Diabetes ?, Anal. Chem. 64 (1992) 381-386.

https://doi.org/10.1021/ac00030a001.

\section{Acknowledgments}

The authors would like to acknowledge CENSIS (Grant No) and the Knowledge Transfer Partnership (Grant No KTP 1024869) for funding this research. All data underpinning this publication are openly available from the University of Strathclyde KnowledgeBase at https://doi.org/10.15129/78e8712e-fa1e-40fc-9727-2d105ae719e3

\section{Conflict of Interest}

The authors have no conflict of interest to report.

\section{CONTRIBUTORS}

LD \& JB connived the idea and designed the experiments. JB undertook the electrochemical and photochemical experimentation. LD, JB \& EF interpreted the data and contributed to the writing of the manuscript.

\section{SUPPORTING INFORMATION}

